\title{
10 Enhancing energy justice in the Arctic
}

\author{
An appraisal of the participation \\ of Arctic indigenous peoples in the \\ transition to renewable energy
}

\author{
Dorothée Cambou \& Greg Poelzer
}

\section{Introduction}

Renewable energy is a key to the transition toward a more sustainable development. The importance of renewable energy both for mitigating the impact of climate change and for helping to alleviate poverty on a global scale is recognised widely. Policy makers also recognise its especial importance in the Arctic region, where temperature is warming twice as fast as the global average. In this context, Arctic states have placed increasing policy emphasis on the development of renewable energy in order to ensure a sustainable development of the region and recognises the importance of Arctic communities' access to energy that is not only cleaner, but also more affordable, accessible, and reliable (SDWG, 2019).

Yet, the full impacts - both positive and negative — of the development of renewable energy for Arctic Indigenous communities require much greater study. At the community level, scholars need to focus more attention to the needs and interests of Arctic communities, who remain heavily dependent on fossil fuels and build a program of inquiry that is systematic and comparative to better understand energy needs and usage within Indigenous communities. At regional and national levels, utility-scale renewable energy projects often pose a conundrum: large-scale hydro, wind, and solar projects serve to meet national objectives to reduce greenhouse gas emissions; however, the siting of these projects are often on the traditional land and territories of Arctic Indigenous peoples, almost invariably infringing on Indigenous well-being, if not also, Indigenous rights (Lempinen \& Cambou, 2018; Cambou,2020). Thus, this situation raises clear concerns about the principles and considerations of basic fairness of the transition to renewable energy as it related to the implications for Indigenous peoples in the Arctic.

The purpose of this contribution is to examine in what extent Indigenous communities currently share the benefits and costs of the energy transition in the Arctic region. While all Arctic states have committed to ensure that "no one will be left behind in the sustainable transition" (UN General Assembly, 2015), this contribution questions the extent of this commitment

DOI: $10.4324 / 9781003172406-10$ 
and its practical effects in relation with Arctic Indigenous peoples. In this regard, the analysis takes a multidisciplinary approach to the question while building upon the concept of energy justice with a specific focus on the rights of Indigenous peoples. Energy justice seeks to identify when and where injustices occur and just opportunities can be realised in order to ensure policy and legal response that contribute to a more representative and inclusive energy decision-making (Sovacool, Burke, Baker, Kotikalapudi, \& Wlokas, 2017). "It calls on academics and practitioners to critically evaluate the implications of energy policies" and "begins with questioning the ways in which benefits and ills are distributed, remediated and victims are recognized" (Heffron, McCauley, \& Sovacool, 2015; McCauley, Heffron, Stephan, $\&$ Jenkins, 2013). Using the concept of energy justice, this contribution relies on legal, policy, and empirical arguments to demonstrate the need to take into account the rights of Indigenous peoples in the transition to renewable energy. In addition, the empirical study of different cases aims to provide a more nuanced analysis of the specific situation and needs of Arctic Indigenous communities to ensure their fair inclusion in the transition to renewable energy in the Arctic. For this purpose, the analysis draws upon different case studies and relies on various sources, including legal texts as well as personal observations and fieldwork experiences. Ultimately, the interpretation of the case studies contributes to improve knowledge about the progress and challenges raised by the energy transition to renewable energy in the Arctic context and further theorise how to ensure a transition that is sustainable and just for all.

In what follows, the chapter first sets out to consider the legal and policy background that links the transition to renewable energy to the social dimension of sustainability and the rights of Indigenous peoples. In this regard, Section I highlights the central tenets, rights and duties attached to the social commitments made by states and business to promote renewable energy as a means to ensure a sustainable and just transition at the international level and highlights the specific status and rights of Indigenous peoples in this context. Next, Section II outlines the broader contexts and corresponding patterns of renewable energy development in the Arctic. Against this backdrop, Section III examines the actual state of play of the energy transition and its impact on Indigenous peoples in the Arctic based on illustrative examples. For this purpose, the contribution examines more particularly the situation of Arctic communities living in Canada, Alaska, Russia, and in the Nordic countries of Norway and Sweden.

\section{A just energy transition for Indigenous peoples: Policy and legal background}

With a few exceptions, a global consensus now acknowledges that the transition from fossil fuel to renewable energy is urgent and critical to address climate change, ensure sustainable development and fulfil human rights. 
Indeed, access to affordable and reliable energy is central to the fulfilment of basic human rights including that of life, food, shelter, health, and education (Tully, 2006; Walker, 2015). In addition, the importance of providing clean energy is increasingly recognised as a baseline to ensure sustainable development. In this regard, the United Nations Sustainable Development Goals (SDG), which provides a set of policy commitments to ensure sustainable development, recognises the central importance of affordable and clean energy "to nearly every major challenge and opportunity the world faces today" (United Nations, 2019). This is more particularly articulated in the implementation of SDG 7, which highlight the need to ensure "access to affordable, reliable, and sustainable energy," and SDG 13, on urgent action to combat climate change that equally requires a transition to a new energy paradigm in which "flow" (renewable) energies are used and consumption is lower and more efficient (UN General Assembly, 2015; Council of Europe, 2011). With the specific mention of sustainable energy in the Agenda for sustainable development, the UN member states therefore recognise the global and urgent need for a transition to renewable energy, in order to achieve sustainable development and address the world's major twenty-first century challenges (Calzadilla \& Mauger, 2018, p. 237).

Paradoxically, however, the transition to renewable energy can also undermine the achievement of the SDGs and adversely affect human rights. For example, research has evidenced the negative impacts of large-scale renewable projects such as hydropower projects and biofuels production on local communities and Indigenous peoples as well as the environment (Zehner, 2012; Cambou,2020). Yet, the issues concerning the social risks and justice concerns of renewable energy continue to be overlooked in the debate concerning the sustainable transition (Calzadilla \& Mauger, 2018, p. 235). In this context research also evidences "how major national energy policy and planning documents concentrate almost exclusively on energy technologies, while social considerations tend to be narrowly economic, focusing on energy prices, jobs and, to some extent, energy access" (Miller \& Richter, 2014, p. 76) and therefore "rarely incorporates justice dimensions" (Healy \& Barry, 2017, p. 452). Thus, although it is argued that "social sustainability' has emerged as a theme in its own right" (Dempsey, Bramley, Power, \& Brown, 2011), the fact remains that the environmental and economic dimensions of sustainability often override social and justice concerns in practice. As a response, an emerging transdisciplinary scholarship on the concept of energy justice is currently being shaped, which highlights the need to integrate "justice" as a meta concept in the narrative of the energy transition (Heffron et al., 2015; Sovacool, Burke, Baker, Kotikalapudi, \& Wlokas, 2017; McCauley et al., 2013).

Beyond its academic foundation, the call for energy justice is also grounded in policy and legal discourses concerning sustainable development and the increasing importance attached to the fact that sustainable development relies upon the golden thread that connects economic development with 
environmental sustainability and social equity. Furthermore, with the adoption of the 2030 Agenda for sustainable development, it is now unequivocally recognised that sustainable development is anchored in human rights: The new Agenda is explicitly aimed to "realize the human rights of all" (preamble) and emphasises "the responsibilities of all States... to respect, protect and promote human rights and fundamental freedoms for all" (UN General Assembly, 2015, para. 19). Additionally, UN Member States have also pledged to ensure "no one will be left behind" and to "endeavour to reach the furthest behind first" (UN General Assembly, 2015, para. 4). In practice, these pledges reflect the fundamental human rights principles of non-discrimination and equality. Applied to the context of the energy transition, these pledges also mean that the transition to renewable energy "require the consideration of social justice in terms of fairness in access and allocation of resources and technologies" (McCauley et al., 2019). They require that the transition to renewable energy, which is grounded in the principle of equity, must be accessible and beneficial for all. In this context, it is also recognised that "addressing the critical needs of indigenous peoples, the elderly, people with disabilities and other marginalized groups is the best way of ensuring that no one is left behind by the 2030 Agenda for Sustainable Development" (UN Department of Economic and Social Affairs, 2017).

Since Indigenous peoples are often among the poorest and most marginalised of the world's population, the UN Agenda for sustainable development calls for specific attention to their situation (UN General Assembly, 2015, para. 23). In this respect, although Indigenous peoples have faced challenges to seeing their interests reflected in the Agenda, the framework highlights that "People who are vulnerable must be empowered" and reflects the needs of Indigenous peoples in several extents in the framework (i.e., four indictors specifically mention Indigenous peoples) (UN General Assembly, 2015). In addition, the UN Permanent Forum on Indigenous Issues has advised that the "the 2030 Agenda must be implemented in full accordance with the United Nations Declaration on the Rights of Indigenous Peoples and other relevant international agreements" (Permanent Forum on Indigenous Issues, 2016). In the context of the energy transition, this means that states must ensure the rights of Indigenous peoples, including their rights to self-determination, to land and natural resources and to maintain their traditional culture. The importance of the right of Indigenous peoples to participate in the energy transition is also enshrined in numerous international instruments, which highlights the duty of states to consult and cooperate in good faith with Indigenous peoples in order to obtain their free and informed consent prior to the approval of any project affecting their traditional lands or territories and other resources (UNDRIP, 2007, art. 32; ILO Convention 169, arts. 6-7). The right of Indigenous peoples to participation based on the principle of FPIC is a core element of their right to selfdetermination, which must be respected and protected by all states and 
respected by corporate actors, especially when energy projects affect their lands and resources and the maintenance of their culture (OHCHR, 2011).

The need to pay attention to the issues of energy justice and to the right of Indigenous peoples to participate in the energy transition is a global issue that finds specific relevance across the Arctic. There are about 500,000 Indigenous peoples living in the Arctic, which represents $10 \%$ of the total population in the region. While there is great diversity of cultural, historical economic and political situations, many communities share legacies of colonisation, the impacts of new industrial processes, and exposure to the effects of pollution and climate change. In addition, many Indigenous communities in the Arctic still lack access to clean and affordable energy or more singularly face the adverse impacts of renewable energy projects. For example, while many Inuit communities struggle to get affordable and clean energy in Alaska, Canada and Greenland, the Sámi reindeer communities who live in Norway, Sweden and Finland face the adverse impacts of renewable energy projects on their traditional territory. Against this background, the following sections explore more closely the situation of Indigenous peoples living in Canada, Alaska, Russia and the Nordic countries in order to identify how Indigenous peoples living in the Arctic participate and benefit from the energy transition.

\section{Renewable energy in the Arctic: Context and patterns}

Before we discuss the respective case studies, it is important first to outline the broader contexts and corresponding patterns of renewable energy development. The Canadian North (territorial and provincial North), Alaska, and the Russian North and Siberia share a significant number of challenges and historical parallels, especially compared to the Nordic countries. First, size and population density matter: Russia and Canada are the two largest countries in the world and, Alaska is the largest state in the United States. To put things into perspective, the state of Alaska is about 1.5 times larger than the territory of Norway, Sweden, and Finland combined, but has less than $5 \%$ of the population of those countries combined. Canada and Russia have comparable territorial size to small population densities. This has a significant bearing on energy infrastructure, particularly electrical grid build-out. Whereas the Nordic countries are almost entirely grid connected on the mainland, most of the territory of Alaska, eastern Siberia, the Canadian territories of Nunavut and the Northwest Territories, and much the provincial North of Canada is not. The cost of erecting and maintaining transmission lines between communities of less than a thousand people that are separated by many hundreds of kilometers is prohibitively expensive. In this regard, it is not surprising that outside the Nordic world, the Circumpolar North has a very high number of off-grid, diesel communities.

Second, legal recognition of Indigenous rights, especially land rights, have significant bearing on Indigenous participation in the electricity 
sector. In Canada, Alaska, and Russia, Indigenous peoples enjoy formally recognised Indigenous land rights not found in the Nordic countries, as well as forms of self-government. Importantly, all three countries are federal countries in contrast to their Nordic Circumpolar neighbors, which on the one hand complicates energy decision-making as a result of jurisdictional complexities, but on the other hand fosters a political culture of multilevel decision-making. The latter creates political space for Indigenous participation in energy decision-making and ownership. Finally, socio-economic gap between Indigenous peoples and the broader society in Canada, Alaska, and Russia is significantly wider that of the Nordic countries. This is a result of a mix of historic factors beyond the scope of this paper. However, what is important to understand is that many Indigenous communities in Canada, Alaska, and Russia confront much higher unemployment rates, lower household incomes, high social pathologies, and lower formal educational attainment than the larger societies. In all three countries, many remote Indigenous communities confront the "heat-or-eat" dilemma as energy costs are often significantly higher than urban centers, even though household incomes of Indigenous communities is often less than half of their urban counterparts. These factors need to be kept in mind as they shape the discourse of energy transition and the role of and impact on Indigenous peoples, especially compared to their Nordic counterparts.

Notwithstanding important commonalities among Canada, Alaska, and Russia, these three cases also have important differences that shape and constrain Indigenous opportunities to achieve greater energy justice. In Canada and Russia, for instance, large-scale public utilities play significant roles compared to Alaska, which has a mix of private, cooperative, and parastatal and no state-wide public utility. In Canada and Russia, there are significant subsidies and cross-subsidies in many provincial and territorial jurisdictions, but Alaska is almost a pure market system in its electrical utility sector, with subsidies limited to consumers downstream and essentially none available for independent power producers. In Alaska, Native Alaskan communities own and operate their own utilities through parastatal or cooperative models; in Canada and Russia, there are no Indigenous owned, generation and distribution utilities, although there are many Indigenous community-owned renewable energy generation projects, operating effectively as small-scale independent or community-owned producers who sell energy to a larger utility. In Alaska, in the absence of a state-wide grid, there is little opportunity for Indigenous communities to participate as utility scale, independent power producers, with the exception of the Railbelt, which has a transmission line that connects Anchorage to Fairbanks. In Canada, however, there are significant opportunities for Indigenous communities to participate in utility-scale power projects, as many of these communities are connected to large-regional or the North American grid.

On the surface, the Nordic welfare state model would appear to apply to the electricity sector, including a shared Nordic grid; however, there are 
important differences between Norway and Sweden. In Norway, as a result of late modern state-building foreign capital and local municipalities played a much larger role in the development of the electricity sector. To this day, there are many more, small municipal and cooperative electricity utilities in Norway compared to Sweden, and a number of these small communities have large Indigenous populations, the Sámi. While the question appears clear when it comes to the conflict between reindeer herding communities and large-scale regional and national energy projects, it is not so clear to what extent the Sámi people in Norway exert control and decision-making power through local parastatal and cooperative electricity institutions. Questions of energy justice are never as clear-cut in the real world as they are in the theory.

\section{The participation of Indigenous peoples in the Arctic energy transition}

The next section of the paper demonstrates how these contexts fundamentally shape patterns of participation by Indigenous communities in current energy transitions. We suggest that four distinct patterns have emerged in the contemporary Circumpolar North: (a) utility-scale projects on Indigenous traditional territory that are opposed by local communities and/or present a threat to indigenous rights ; (b) utility-scale projects (typically projects in the order of $10 \mathrm{MW}$ or larger and is sold to a large-scale grid-connected utility) in which Indigenous peoples are owners or co-owners of the project; (c) community-scale projects driven by national and regional governments or public utilities; (d) community-scale projects driven by communities (typically less than $1 \mathrm{MW}$ and intended to serve the immediate needs of a small community). Canada has examples of all four patterns; Alaska (b) and (d); Russia (a) and (c); and the Nordic countries mainly a), but with some qualifications as it relates to (b) and (d). It should be apparent, that pattern a) does meets least, if at all, any notions of energy justice for Indigenous peoples; pattern c) meets better energy justice goals; but, clearly patterns (b) and (d) are the most robust in achieving energy justice, as Indigenous peoples are able to participate in energy decision-making on a much more level playing field and accrue the benefits that come from those projects to improve the well-being of their communities. Below, this paper outlines specific examples in each of Canada, Alaska, Russia, and the Nordic countries.

\section{Canada}

Canada may have the most complex story among these cases. For most of the twenty-first century, the legacy of renewable energy development was dominated by utility-scale hydro-electric projects, for industrialisation and resource development, domestic and international exports markets, and residential consumers. Indeed, hydro-electricity accounts for $60 \%$ of Canada's 
total electrical production. The Kemano Hydro facility in the northern British Columbia, for instance, was built for the sole purpose of producing electricity for an aluminium smelter in the town of Kitimat. Island Falls Hydro facility was built in the northern Saskatchewan to power mining and smelting in northern Manitoba. The James Bay project in northern Quebec was built not only to serve domestic needs in the province, but also as an export, primarily to New York State and the Eastern seaboard of the United States. All of the facilities generated and, in some cases, continue to generate significant controversies with Indigenous peoples. The large-scale projects in Manitoba and Quebec, in particular, flood tens of thousands of hectares of Indigenous traditional lands, changing hunting and fishing patterns, transportation, among other things. Although many of these legacy hydro projects have produced impact benefit agreements and, in the historic case of James Bay, land claims settlements and Indigenous self-government, there are several notable cases still under litigation.

The policy environment in Canada today is radically different from the preceding century, with three new developments shaping the energy transition toward a low-carbon future: climate change and Canada's commitments to the Paris Agreement; the United Nations sustainable development goals; and, seeking Reconciliation between the Crown and Canada's Indigenous peoples. The developments may and often reinforce positively energy transitions and energy justice for Indigenous people; they can also be at odds. This becomes evident when we contrast national and provincial policy imperatives with those of local Indigenous communities.

At the national level, Canada already has a high level of electricity produced by non-emitting sources at approximately $80 \%$ (65\% from renewable energy, most of which is hydro-electricity, and 15\% from nuclear energy). Nevertheless, Canada intends to meet the goals of reaching $90 \%$ by 2030 and eventually $100 \%$ of electricity from non-emitting sources. These goals align with both Paris commitments, as well as the UN Sustainable Development Goals. Meeting these goals will require adding tens of thousands of MW of capacity through large, utility-scale energy projects. This has the potential to conflict with Indigenous land rights, if not done properly. Done properly, meeting this goal opens up new avenues for reconciliation with Indigenous peoples through "steel in the ground" by creating equity ownership opportunities and long-term, sustainable revenue and employment streams.

At the local level of Indigenous communities, a very different picture emerges: clean energy generation and its benefits are distributed highly unevenly; so, too, are the costs. Canada has more than 280 off-grid diesel communities representing 200,000 Canadians, 144 of these communities are Indigenous; in other words, Indigenous people constitute about $5 \%$ of the Canadian population, but represent $50 \%$ of the off-grid diesel communities. Remote communities typically experience the highest energy costs, even though they are also the poorest in Canada. In Nunavut, for instance, communities have "electricity costs subsidized at 28.4 cents per kilowatt 
hour (kW.h) for the first $1,000 \mathrm{~kW} . \mathrm{h}$ per month in the winter or the first $700 \mathrm{~kW}$.h per month in the summer. If electricity consumption exceeds these amounts, the consumer is charged the unsubsidized rate" (National Energy Board, 2018). The unsubsidised rates vary by community; for instance, the rate is 56.7 cents per $\mathrm{kWh}$ in Iqaluit and 112.3 cents per $\mathrm{kWh}$ in Kugaaruk (National Energy Board, 2018). By comparison, the rate for residents in Saskatchewan in 14.5 cents per $\mathrm{kWh}$. If the energy justice is to be achieved for Indigenous communities, then meeting clean energy sustainable development goals means addressing not only the "clean" part of renewable energy, but also increasing energy access and energy security. Renewable energy almost by definition means local energy, potentially reducing both transportation costs and risks of interrupted supply chains. Renewable energy holds the promise of the reducing energy costs for communities with the lowest household incomes. Locally produced energy also provides opportunities for increased, sustainable employment, thus raising household incomes, if only modestly across a community as a whole.

Given the above context, it is no surprise that all four patterns outlined in the previous section of the paper are found in Canada. We briefly provide examples of each below.

Meeting Paris commitments and the Clean Energy SDG continues to lead to contestation between utility-scale renewable energy and Indigenous rights. From a greenhouse emissions perspective, hydro-electric power is one the best options for renewable energy development. Upfront capital costs are generally very high, but operational costs per $\mathrm{kWh}$ are among the lowest over the long term. Importantly, in contrast to wind and solar, hydro-electricity has the huge advantage of providing dispatchable generation and with capacity factors typically five times greater than solar and at least double that of wind, even with advances in wind technology. Hydro-electricity also has the advantage of providing flood control to help mitigate due to extreme weather events, which are becoming increasingly common due to climate change.

Notwithstanding the advantages, in Canada, the conventional wisdom is that mega-projects and even large-scale, conventional hydro-electric dam development is largely a relic of the past. There are many excellent sites for hydro development in Canada that are technically accessible but politically inaccessible. Environmental requirements, Indigenous rights claims, and public social licence requirements, among other things, make such projects very difficult to advance. However, two notable cases prove the exception to the rule: Site C Dam in northern British Columbia and Muskrat Falls in Labrador. Both of the cases have resulted in political and legal challenges from Indigenous communities affected by the development of these projects. (For details on these cases, please read Buhmann et al., Chapter 9.)

Utility-scale electricity projects, however, are also points of reconciliation rather than conflict. Increasingly, Indigenous peoples in Canada are seeking opportunities to be independent power producers. Two innovative developments, among many to date, deserve special note: First Nations Power 
Authority and Wataynikaneyap Power. The First Nations Power Authority was created through agreement of the Government of Saskatchewan and the Federation of Sovereign Indigenous Nations in the province of Saskatchewan to facilitate the participation of Indigenous communities in the electricity sector and to provide a formalised pathway for working the publicly-owned crown utility, SaskPower. In its own words, "First Nations Power Authority (FNPA) was established as a not-for-profit to create a landscape favorable to Indigenous inclusion in the power sector. Created in 2011, FNPA was mandated to facilitate the development of First Nations led power projects and promote Indigenous participation in procurement opportunities with the crown utility in Saskatchewan, SaskPower" (FNPA, 2019). The Province of Saskatchewan has a public goal of obtaining 50\% of its electricity from renewable energy by 2030 from a starting point of $24 \%$. SaskPower is providing set-asides to FNPA to procure electricity from greenfield renewable energy projects that are majority owned by First Nations communities. Although FNPA started with smaller pilot renewable energy projects, it has now successfully tendered two utility-scale solar projects, $10 \mathrm{MW}$ that will be owned by Cowessess First Nation and another $10 \mathrm{MW}$ jointly-owned by Starblanket Cree Nation and George Gordon First Nation. First Nation Power Authority also has $20 \mathrm{MW}$ set aside for turning waste flare gas into recovered energy for electricity production. The goal for FNPA is to continue to increase the independent power producer opportunities for Indigenous communities not only in Saskatchewan, but across Canada, and FNPA has been very active with community energy planning with First Nation in the neighboring province of Alberta.

The construction of transmission lines is often a source of contention with Indigenous communities. Wataynikaneyap Power provides a counter example. In Northern Ontario, there are 32 electrically remote communities, 25 of which are First Nations communities. A provincially commissioned study determined that creating a transmission line to connect 16 of these communities would create a net savings in diesel of more than $\$ 1$ billion over the next 40 years. In addition, it would provide an opportunity to upgrade an outdated transmission line connecting those services with 5 additional communities. Whereas other Northern Ontario grid connected communities experienced approximately 3 outages per year, those on the outdated line experienced 14 unplanned outages per year. This is particularly hard for households that rely on electricity for their primary or even supplemental heating during winter months that commonly go to 40 degree below zero. The solution was to invest in a $\$ 1.6$ billion transmission line connecting 17 off-grid communities and, in the process, upgrading the transmission to the 5 grid-connected communities. The new transmission line be owned and operated as Wataynikaneyap Power LP with the 22 communities as the owners of Wataynikaneyap Power LP. The creating of this transmission utility achieves not only Clean Energy SD goals by taking 17 communities off diesel, but also achieves energy justice by providing reliable and affordable 
power and by providing Indigenous ownership and control over electricity transmission infrastructure.

Canada is not only making progress toward great energy justice in electricity generation and transmission, but also in local Indigenous clean energy generation. The federal government has launched to programs to eventually reduced or eliminate the reliance on diesel generators in Canada's more than 280 off-grid communities, half of which are Indigenous. To that end, the Government of Canada has committed more than $\$ 800$ million for remote and Indigenous communities to develop local renewable energy generation projects, primarily for electricity, but also for biomass heating. Rather than the Government of Canada dictating to communities their energy choices, communities apply for funding for energy projects that they would like to see developed for and owned by their communities. Projects are assessed on the financial and technical feasibility by reviewers external to the Ministry. Critically, proposals must include a capacity-building plan to operate and maintain community energy projects. In addition, the Government of Canada has invested in training programs such as the 2020 Catalyst Program, which provides training to Indigenous participants so they have the capacity to lead community energy planning in their home communities. Although the program is in its beginning two years as of 2019, already dozens of projects have been funded by the federal government, including a $\$ 40$ million wind turbine project to be sited near the Arctic community of Inuvik, Northwest Territories, lead and owned by the Gwich'in.

\section{Alaska}

Alaska is unique within the Circumpolar North. It is the story of more than a half a century of Indigenous owned and operated electric utilities. No part of the State of Alaska is connected to the North American electrical grid. And, outside of the Railbelt, the only major regional transmission grid connection Fairbanks to Anchorage and its local environs, and of the immediate Juneau area, no communities in Alaska are connected to an electrical grid. Moreover, there is not state-wide public or private electric utility. There are approximately 90 electric utilities spanning private, parastatal, and cooperative. In Alaska, about $45 \%$ of the electricity comes from natural gas, $25 \%$ from hydro, $15 \%$ from oil and the other $15 \%$ of the electric capacity comes from predominantly a mixture of coal, wind and biomass (EIA, 2018). Due to their dependence on fossil fuel, scarce transportation infrastructure and great distances between communities, Alaskans also pay nearly double the national average for energy, which cause or exacerbate social, economic and environmental issues at the local level.

However, there is also significant momentum in community-level renewable energy project in Alaska. Among the numerous success stories, two electricity stories exemplify Native Alaskan ownership and self-determination: the Alaska Village Electric Cooperative (AVEC) and Cook Inlet Region Incorporated (CIRI) Fire Island project. 
AVEC was created in 1967 as Native Alaskan owned electricity cooperative. Since 1967, it has grown to include 57 Native Alaskan communities and is the largest electricity cooperative in the world by territory. The cooperative model has been highly successful and uses economies of scale and pooling of resources to operate an efficient and reliable utility in one of the most challenging environments in the world. One of the major challenges of remote communities is affording technicians who can operate generation systems, especially highly variable renewable energy systems. One of the solutions is a circuit rider program in which technicians are shared among communities and visit communities for repair and maintenance on a regular and scheduled basis. AVEC has been very successful in integrating renewable energy generation in small communities with diesel generation, especially wind power and it has been on the forefront of cutting-edge technologies such as the adoption of smart meters and prepaid card for using electricity in the home. These measures have resulted in greater energy literacy among many residents of AVEC served communities, certainly higher than that of most larger urban centers in North America or Europe. All of this has been achieved in the closest example market system with little operating subsidies, certainly compared to Canada, Russia, or the Nordic countries.

CIRI is the regional cooperation, formed out of the 1971 Alaska Native Claims Settlement Act. CIRI represents Native Alaskan beneficiaries in the Cook Inlet areas, including individuals of Athabascan, Southeast Indian, Inupiat, Yup'ik, Alutiiq/Sugpiaq and Aleut/Unangax descent. CIRI is an example of a global leader in Indigenous independent power production. CIRI constructed, owns, and operates a $17.6 \mathrm{MW}$ wind farm on Fire Island just outside of Anchorage. It is the first independent power producer in the region and has a 25-year power purchase agreement with the Anchoragebased utility, Chugach Electric Association. The eleven turbines have the capacity to provide electricity to the equivalent of 7,000 homes. CIRI not only is the owner of this project, but also has equity positions in renewable energy projects in the continental United States, thousands of kilometres away. CIRI demonstrates that Indigenous peoples and communities can be owners and drivers in the global energy transition.

With its increasing number of renewable energy facilities, the transition to renewable energy is underway in Alaska. Yet, it remains to be seen whether this development will be sufficient to achieve the goal to generate $50 \%$ of Alaska's electricity from renewable energy before 2025 and enhance energy security and sustainability for all Indigenous communities in the region.

\section{Russia}

Indigenous communities in the Russian North and Siberia share many of the level energy security challenges with similar communities in Canada and Alaska; they also share the same challenges that large-scale renewable energy projects present to traditional ways of life, especially hydro-electric development, with Indigenous communities in the Nordic countries. 
However, it may come as a surprise to many, but Russia is also home to important advances toward greater energy justice and meeting the Clean Energy SDG, notably in the Sakha Republic (Yakutia), located in eastern Siberia, which constitute about one-fifth of the entire territory of the Russian Federation. These advances include renewable projects and assessment processes, which are contributing to create greater energy security in Northern Indigenous communities and also accommodate Indigenous needs surrounding utility-scale greenfield energy development.

Among these advances, projects concerning Russian energy supply are notable. Although higher energy costs present significant challenges to Indigenous households, energy supply may be an even more threat to achieving energy security. Many remote communities in the Russian Arctic and Siberia depend on shipping supply lines to provide basic necessities, especially fuel for heating and for diesel electric generation. The supply lines are complex and require shipping along the Northern Sea Route and along major river systems such as the Lena. Weather conditions can result in significant delays and even missed shipping seasons, placing communities in highly vulnerable positions. To address both costs and vulnerabilities, Sakhaenergo (Sakhaenerg is a subsidiary of PJSC Yakutskenergo, part of the RAO Energy Systems of the East holding company) has taken the initiative to build and deploy significant solar arrays in some of the most remote communities that Sakhaenergo serves. In fact, the largest solar facility in the Arctic is located in Batagay, located in northern Sakha Republic (Yakutia) over $1 \mathrm{MW}$ in installed capacity. Beyond the ground-breaking Batagay facility, Sakhaenergo has deployed solar arrays in 16 communities with an additional total installed capacity of 1.47 MW (Bellini, 2019). Although these efforts clearly address Indigenous energy security, the decisions to build and operate are top-down, not bottom-up, and there is no ownership by local communities. This case therefore fits pattern "c" of Indigenous participation, due to the lack of agency provided for Indigenous peoples in the development of the project.

The Sakha Republic (Yakutia) has also served as a pilot region within the Russian Federation for undertaking environmental impact assessment and innovative social impact assessments, the latter through a formal legally established process called Ethnological Expertise, which is overseen by an Expert Committee, whose composition includes appointments made by republic level Association of the Small-Numbered Peoples of Yakutia. To date, this process has reviewed applications for industrial resource development on approximately 50 projects (three of which include, in 2012, the proposed Cancun Hydro-electric station on the Timpton River in the southern part of the republic and, in 2013, two transmission lines, also in southern Yakutia). The Expert Committee found that RusHydro, the proponent of the Cancun HPS project, had not assessed the impact on traditional livelihoods and deemed the proponent's assessment as inadequate and grossly underestimated appropriate levels of compensation owed to Indigenous 
communities affected by the proposed project. It also placed as further requirement "a full environmental and social impact assessment be conducted during the construction of the Cancun HPS" (Sleptsov, 2015, p. 94). The proponent revised its submission; it was reassessed, and was approved by the Expert Committee. In the case of the transmission lines, the Expert Committee approved the applications. Although important challenges remain in the Russian Arctic to consolidate Indigenous peoples'rights, it is suggested that this level of Indigenous agency in approval processes represents a progress in institution building to ensure energy justice for Indigenous peoples (Sleptsov, 2015).

\section{Norway and Sweden}

In comparison with other Arctic states, the Nordic countries have already emerged to be leaders in renewable energy and efficiency, with all countries aiming to be virtually fossil free by 2050 (Sovacool, 2017). However the energy transition is not without its own cost and has raised a number of social issues, more specifically in relation to the rights of the Sámi Indigenous people, who live as a minority group across the territory of Norway, Sweden, Finland and the Kola Peninsula of Russia.

Paradoxically, the transition to renewable energy to promote sustainable development is among the issues that jeopardise the sustainability of Sámi livelihoods due to the adverse impacts of renewable energy projects on their traditional land and resources. Historically, it was the impact of large-scale hydroelectric projects that spurred the first opened conflicts between the Nordic governments and the Sámi people in the energy context. The transition to hydroelectric energy was grounded in the policy needs for increasing energy supply and ensures self-sufficiency in order to guarantee the industrialisation and modernisation of the nation states. However, the development of these projects had also for adverse effect to damage the traditional land and resources of Sámi communities. In the beginning of the twenty century, the construction of the first stage of the great reservoir at Suorva in northern Sweden, signed for example the beginning of an extensive encroachment on reindeer husbandry and Sámi culture (Ö́ssbo \& Lantto, 2011, p. 330). In Norway, the conflict of the Alta-Kautokeino hydropower project, which began in the 1970s is also notorious and has served to expose the lack of recognition of the rights of the Sámi as an Indigenous people in the energy context and more generally in mainstream national politics (Howitt, 2002, p. 280; Paine, 1982).

Today, the rights of the Sámi people have also become an issue of controversy in the context of the transition to renewable energy. This is more particularly due to the development of wind energy projects and their adverse effects on reindeer herding. The establishment of wind turbines has multiple effects on reindeer herding (Skarin, 2016). It can affect the migration of reindeer, disturb grazing and calving areas and increase the workload and cost 
of activities for reindeer herders. With the multiplication of onshore wind energy projects, Sámi reindeer herding communities also face the cumulative effects of projects, which are magnified by the impacts of other industrial development processes. Several UN reports have criticised the impact of these projects on the traditional livelihoods of the Sámi (UN report \& Anaya, 2011; UN Report \& Tauli-Corpuz, 2016). Renewable projects have also led to an increasing number of court cases highlighting the responsibility of companies to mitigate the impact of wind energy in the purpose to allow co-existence between reindeer herding and the development of wind energy projects (Cambou, 2020).

Among the numerous projects that are currently being opposed by Sámi reindeer communities, two large renewable energy projects stand out due to their large-scale impacts at the local level: the Fossen project in Norway and the Markbygden project in Sweden.

With its 273 planned turbines, the Fossen project constitutes one of the largest onshore wind projects in Europe. The Norwegian Petroleum and Energy Ministry gave its approval for the construction of the project in 2017 despite important concerns, protests and court petitions from the southern reindeer herding communities, who have traditionally used the land where the project is being built. The project was also authorised in defiance to the request of the UN Committee on the Elimination of Racial Discrimination, which asked Norway to temporarily suspend the project in order to examine a complaint from Sámi communities (CERD, in Reuters, 2018). In the view of the Norwegian ministry, the fact that the project has successfully met all legal national requirements and also survived a number of court petition justified the authorisation of the project. The project is currently underway and should be completed by 2020 .

In Sweden, the development of renewable energy has also raised important issue in relation to reindeer herding. Sweden aspires to be a leader in the transition to renewable energy and for this purpose has set the target to produce $100 \%$ renewable electricity by 2040 . In this context, wind energy represents an important tool to achieve this goal, which has materialised with an increase of wind energy projects being established in the country. In the northern most counties, where the Sámi reindeer herders' territories is located, the amount of wind turbines has increased from approximately 1,000 to more than 3,000 turbines between 2008 and 2018. While this development is supported by a growing number of small and medium projects, the Markbygden project represents by itself 1001 turbines, which is approximately $7 \%$ of the share of total electricity generation in Sweden. Despite several court cases against the project and protests from Sámi reindeer communities, the project has been authorised by the government and is planned to be completed by 2021 .

The Fossen and Markbygden cases epitomise pattern (a) of participation by Indigenous communities in renewable projects in so far as these projects create conflict and present a threat to Indigenous rights. In order to ensure a just transition, the current challenge for the Nordic governments therefore 
remains to ensure that the transition to renewable energy does not adversely affect the Sámi Indigenous people by undermining their right to maintain their traditional culture.

\section{Conclusion}

The global energy transition toward a low carbon future means significant investment in renewable energy. But green energy is only good energy if generated properly and for the benefits of all people. In this regard, Indigenous peoples confront two main challenges, one from new, large-scale renewable energy projects that have the potential to undermine Indigenous land rights and traditional livelihoods; and the struggle to secure affordable and reliable energy in their communities. At the very core is the question of how can energy justice be achieved for Indigenous peoples in this transition, a transition that fundamentally affects the rights and well-being of Indigenous peoples living in the Arctic.

In this analysis, four patterns of participation by Indigenous communities in the current energy transitions were identified: (a) utility-scale projects on Indigenous traditional territory that are opposed by local communities and present a threat to Indigenous rights; (b) utility-scale projects in which Indigenous people are owners or co-owners of the project; (c) community-scale projects driven by national and regional governments or public utilities; (d) community-scale projects driven by communities. At the outset, this analysis demonstrates that many Indigenous peoples continue to encounter pattern (a) in all Arctic states as a result of their opposition and/ or lack of adequate participation in the development of large-scale renewable development projects, which do not meet their community demands in energy and encroach on their rights This situation is more particularly illustrated in the case of the Site C Dam and Muskrat Falls in Canada, the Fossen project in Norway and the Markbygden project in Sweden. However, we also have seen cases where projects meet indigenous energy security needs but where participation is not adequately accommodated (e.g. Sakha Yakutia) notably because these projects fall short of enabling Indigenous agency_ownership and control—over local energy generation.

In contrast, this contribution also identified patterns (b) and (d) of participation that are more adequate in achieving energy justice for Indigenous peoples. When Indigenous peoples act as owner or drivers of renewable energy projects and are therefore able to participate in energy decision-making and accrue the benefits that come from those projects for improving the wellbeing of their communities, there is more certainty to achieve the sustainable developments goals and ensure energy justice for Indigenous communities. Yet, the development of such participation pattern remains insufficient today. This paper recommends that Arctic states at both the national and regional levels proactively develop robust institutional arrangements and policy environments that promote solutions that follow patterns (b) and (d) 
in accordance with the rights of Indigenous peoples, in particular their right to maintain their traditional culture. As this paper has shown, patterns (b) and (d) are not merely possible but are already in practice. If the Arctic states strive to promote energy justice, they will in so doing provide a global model for other regions on our planet to emulate as countries seek appropriate pathways to achieve the Clean Energy Sustainable Development Goal and contribute to combat climate change and its impacts.

\section{References}

Bellini, E. (2019, February 26). Floating solar reaches new territories. PV Magazine. https://www.pv-magazine.com/2019/02/26/floating-solar-reaches-newterritories/

Buhmann, K., Bowles, P., Cambou, D., \& Skjervedal, A. S. H. (2020). Towards socially sustainable renewable energy projects through involvement of local communities: Normative aspects and practices on the ground. In D. Natcher \& T. Koivurova (Eds.), Renewable economies in the Arctic: A state of knowledge. Routledge.

Calzadilla, P. V., \& Mauger, R. (2018). The UN's new sustainable development agenda and renewable energy: The challenge to reach SDG7 while achieving energy justice. Journal of Energy \& Natural Resources Law, 36(2), 233-54. doi: https://doi.org/10.1080/02646811.2017.1377951.

Cambou, D. (2020). Uncovering Injustices in the Green Transition: Sámi rights in the development of wind energy in Sweden. Arctic Review on Law and Politics, 11, 310-333. doi: https://doir.org/10.23865/arctic.v11.2293.

Council of Europe. (2011). Energy supply and energy efficiency at local and regional level: promoting energy transition (S. Orlova, Rapp.). Council of Europe, $21^{\text {st }}$ session, CG (21)11, Russian Federation.

Dempsey, N., Bramley, G., Power, S., \& Brown, C. (2011). The social dimension of sustainable development: Defining urban social sustainability. Sustainable Development, 19(September), 289-300. doi: https://doi.org/10.1002/sd.417.

Energy Information Administration (EIA). (2018). "Alaska. State Profile and Energy Estimates". US Energy Information Administration. https://www.eia.gov/ state/analysis.php?sid=AK\#71

First Nations Power Authority (FNPA). (2019). About FNPA. FNPA. https://fnpa. ca/about-fnpa/

Healy, N., \& Barry, J. (2017). Politicizing energy justice and energy system transitions: Fossil fuel divestment and a "Just Transition". Energy Policy, 108(September), 451-59. doi: https://doi.org/10.1016/j.enpol.2017.06.014.

Heffron, R. J., McCauley, D., \& Sovacool, B. K. (2015). Resolving society's energy trilemma through the energy justice metric. Energy Policy, 87(December), 168-76. doi: https://doi.org/10.1016/j.enpol.2015.08.033.

Howitt, R. (2002). Rethinking Resource management: Justice, sustainability and indigenous people. Routledge.

Lempinen, H., \& Cambou, D. (2018). Energy security in the barents region: A focus on societal perspectives. In K. Hossain \& D. Cambou (Eds.), Society, environment and human security in the Arctic barents region (pp. 118-133). 
McCauley, D. A., Heffron, R. J., Stephan, H., \& Jenkins, K. (2013). Advancing energy justice: The triumvirate of tenets. International Energy Law Review, 32(3), 107-10.

McCauley, D., Ramasar, V., Heffron, R. J., Sovacool, B. K., Mebratu, D., \& Mundaca, L. (2019). energy justice in the transition to low carbon energy systems: Exploring key themes in interdisciplinary research. Applied Energy, 233-234(January), 916-21. doi: https://doi.org/10.1016/j.apenergy.2018.10.005.

Miller, C. A., \& Richter, J. (2014). Social planning for energy transitions. Current Sustainable/Renewable Energy Reports, 1(3), 77-84. doi: https://doi.org/10.1007/ s40518-014-0010-9.

National Energy Board. (2018). Market Snapshot: Overcoming the challenges of powering Canada's off-grid communities. Canada Energy Regulator. https:// www.neb-one.gc.ca/nrg/ntgrtd/mrkt/snpsht/2018/10-01-1cndffgrdcmmnts-eng. html?=undefined\&wbdisable=true

OHCHR. (2011). Guiding Principles on Business and Human Rights: Implementing the United Nations "Protect, Respect and Remedy" Framework (HR/ PUB/11/04). OHCHR. https://www.ohchr.org/Documents/Publications/Guiding PrinciplesBusinessHR_EN.pdf.

Össbo, Å, \& Lantto, P. (2011). Colonial tutelage and industrial colonialism: Reindeer husbandry and early 20th-century hydroelectric development in Sweden. Scandinavian Journal of History, 36(3), 324-48. doi: https://doi.org/10.1 080/03468755.2011.580077.

Paine, R. (1982). Dam a River, damn a people?: Saami. International Work Group for Indigenous Affairs.

Permanent Forum on Indigenous Issues. (2016). Substantive Inputs to the High Level Political Forum on Indigenous Issues: Thematic Review of the 2030 Agenda for Sustainable Development. UN Sustainable Development.

Reuters. (2018, December 21). Norway to build wind farm despite concerns of reindeer herders. Reuters. https://www.reuters.com/article/us-norway-windun-idUSKCN1OK1WS

SDWG. (2019). Arctic Sustainable Energy Futures: The Arctic Community Energy Planning and Implementation (ACEPI) Toolkit Final Report. Arctic Council. https://oaarchive.arctic-council.org/handle/11374/2301.

Sleptsov, A. (2015). Ethnological expertise in Yakutia: Regional experience of legal regulation and enforcement. Northern Review, 39, 88-97.

Sovacool, B. K. (2017). Contestation, contingency, and justice in the Nordic low-carbon energy transition. Energy Policy, 102(March), 569-82. doi: https://doi. org/10.1016/j.enpol.2016.12.045.

Sovacool, B. K., Burke, M., Baker, L., Kotikalapudi, C. K., \& Wlokas, H. (2017). New frontiers and conceptual frameworks for energy justice. Energy Policy, 105(June), 677-91. doi: https://doi.org/10.1016/j.enpol.2017.03.005.

Skarin, A. et al. (2016). Renar och Vindkraft II - Vindkraft i drift och effekter på renar och renskötsel. Swedish University of Agricultural Sciences

Tully, S. (2006). The contribution of human rights to universal energy access. Northwestern Journal of Human Rights, 4(3), 518.

UN Department of Economic and Social Affairs. (2017). Reaching the furthest behind first is the answer to leaving no one behind. United Nations Department of Economic and Social Affairs (UN DESA). https://www.un.org/development/ desa/en/news/sustainable/reaching-furthest-behind.html. 
UN Report \& Anaya, J. (2011a). Report of the Special Rapporteur on the Rights of Indigenous Peoples Extractive Industries Operating within or near Indigenous Territories (UN Doc. A/HRC/18/35). United Nations.

UN Report \& Anaya, J. (2011b). The situation of the Sami people in the Sápmi region of Norway, Sweden and Finland (UN Doc. A/HRC/18/35/Add.2). United Nations.

UN Report \& Tauli-Corpuz, V. (2016). Special Rapporteur on the rights of indigenous peoples on the human rights situation of the Sámi people in the Sápmi region of Norway, Sweden and Finland (UN Doc. A/HRC/33/42/Add.3). United Nations.

UN General Assembly. (2015). Transforming our world: The 2030 agenda for sustainable development. United Nations. https://doi.org/10.1891/9780826190123.ap02.

United Nations. (2019). Sustainable development goal 7. United Nations. https:// www.un.org/sustainabledevelopment/energy/.

Walker, G. (2015). The right to energy: Meaning, specification and the politics of definition. L'Europe En Formation, 378(4), 26-38.

Zehner, O. (2012). Green illusions: The dirty secrets of clean energy and the future of environmentalism. University of Nebraska Press. 